\title{
In vitro Antibacterial Activity of Zingiber officinale and Orthosiphon stamineus on Enterococcus faecalis
}

\author{
Zamirah Zainal-Abidin ${ }^{1}$, Nor Akmal Abdul-Wahab ${ }^{1}$, Muhamad Kamil Ghazi-Ahmad ${ }^{1}$ \& Shahida Mohd-Said ${ }^{1}$ \\ ${ }^{1}$ Faculty of Dentistry, Universiti Kebangsaan Malaysia, Kuala Lumpur, Malaysia \\ Correspondence: Zamirah Zainal-Abidin, Faculty of Dentistry, Universiti Kebangsaan Malaysia, Kuala Lumpur \\ 50300, Malaysia. E-mail: zamirah@ukm.edu.my
}

Received: October 3, 2017

Accepted: December 21, 2017

Online Published: December 31, 2017

doi:10.5539/jas.v9n13p112

URL: https://doi.org/10.5539/jas.v9n13p112

\begin{abstract}
This study evaluates the antibacterial effects of Zingiber officinale essential oil and Orthosiphon stamineus water extract against Enterococcus faecalis. The herbs were prepared in various concentrations to determine their minimum inhibitory concentrations (MIC) and growth inhibitory effect. Anti-adhesion activities of the herbs were determined by co-incubation with E. faecalis cultures for 6 and $24 \mathrm{~h}$. Biofilm disruption activities were determined by adding the studied herbs into preformed $E$. faecalis biofilm. The effects on the morphology of $E$. faecalis grown as biofilm were studied using scanning electron microscopy (SEM). The MICs of ginger oil and $O$. stamineus extract were 0.31 and $25 \mathrm{mg} / \mathrm{mL}$, respectively. Between the tested herbs, ginger exhibited greater inhibitory effects on the growth of E. faecalis grown in suspension mode. Both herbs generally showed anti-adhesion activities in inverse concentration-dependent manner. No significant biofilm disruption activities by both herbs were observed. SEM analyses showed E. faecalis cell surface changes in the treated biofilm. The studied herbs may have compromised the integrity of the bacterial cell membrane. These findings suggest that the studied herbs may have better antibacterial activities against $E$. faecalis in suspension mode compared to biofilm mode, with ginger oil showed greater antibacterial activity compared to $O$. stamineus extract.
\end{abstract}

Keywords: Zingiber officinale, Orthosiphon stamineus, Enterococcus faecalis, antibacterial

\section{Introduction}

Dental caries and periodontal disease are two of the most prevalent oral health problems worldwide (Kassebaum et al., 2017). The main cause of these conditions is bacterial infection from the dental plaque. Amongst the common pathogenic species involved in both conditions are Enterococcus faecalis, a facultative anaerobic bacteria and notoriously known to be resistant to antibacterial and clinical therapy (Stuart et al., 2006). Recent findings in drug discovery research using herbal extracts have given new hopes for supplemental or even alternative approach to managing dental infections more effectively and safely.

Zingiber officinale (ginger) from the Zingiberaceae family, is an aromatic rhizomatous plant grown throughout Asia and tropical regions (Sasidharan \& Menon, 2010; Imtiyaz et al., 2013). It has been used as medicine for diarrhoea (Imtiyaz et al., 2013), and nausea caused by motion and morning sickness, as well as chemotherapy (Lete \& Allué, 2016). The active components of ginger such as gingerol, volatile oil, shaogol and diarylheptanoids have been reported to exhibit anti-inflammatory, antioxidant, antilipid, antidiabetic, analgesic, antipyretic and anticancer activities (Kim et al., 2008; Sasidharan \& Menon, 2010; Shim et al., 2011, Imtiyaz et al., 2013, Ghasemzadeh et al., 2016). Ginger has also been reported to exhibit strong antibacterial effects against several pathogens such as Escherichia coli, Proteus spp., Staphylococcus spp. (Karuppiah \& Rajaram, 2012), Streptococcus spp (Sebiomo et al., 2011; Azizi et al., 2015), Pseudomonas aeruginosa (Kim \& Park, 2013) and Candida albicans (Takahashi et al., 2011). Recently, there have been reports on the use of ginger in dentistry (Ficker et al., 2003; Atai et al., 2009; Patel et al., 2011).

Orthosiphon stamineus, also known as "misai kucing" (cat's whiskers) in Malay, is a medicinal herb belonging to the family Lamiaceae. O. stamineus is widely used traditionally for the treatment of various disorders, such as those affecting the urinary tract, diabetes, gout, rheumatism and jaundice (Perry, 1980). The beneficial $O$. stamineus chemical compounds are polymethaxylated flavonoids such as sinensetin, eupatorine and caffeic acids derivatives, which include rosmarinic acid, cichoric acid and caffeic acid (Tezuka et al., 2000; Olah et al., 2003; Mohamed et al., 2012). It has been reported that 50\% methanolic extract of $O$. stamineus showed protective 
effects against alcohol-induced gastropathy, liver damage, pyrexia (Yam et al., 2007, 2009a, 2009b), anti-inflammatory and analgesic effects (Yam et al., 2008). Studies on the antimicrobial activity of $O$. stamineus have been reported against Staphylococcus aureus, Streptococcus agalactiae and Vibrio parahemolyticus (Ho et al., 2010; Mohammed et al., 2012).

Although these studies have shown the beneficial effects of both plants, little is reported on the antibacterial properties of these herbs in the field of dentistry, especially on bacteria implicated in periodontal and endodontic diseases like the notoriously resistant Enterococcus faecalis. This study will help to appreciate the antibacterial properties of $Z$. officinale and $O$. stamineus toward $E$. faecalis in suspension culture as well as in biofilm environment. Therefore, the aim of this research was to investigate the antibacterial effects of $Z$. officinale and $O$. stamineus on E. faecalis. The findings on the structural changes of E. faecalis after exposure to these two herbs, using scanning electron microscopy (SEM) was also reported.

\section{Materials and Methods}

\subsection{Preparation of Ginger and O. stamineus}

Ginger essential oil was obtained from the Drug Discovery Research Laboratory of Universiti Kebangsaan Malaysia (courtesy of Dr. Shahida Mohd Said). Briefly, ground ginger was boiled for $8 \mathrm{~h}$ in the boiling flask with a tight-fitting adapter attached to the aspirator vacuum. The volatile components of the samples were evaporated with steam and cooled as oil at the end of the procedure. The oil was then collected, and remaining water was removed using anhydrous sodium sulphate. O. stamineus powder was obtained from Faculty of Bioprocess, Universiti Teknologi Malaysia, Skudai, Johor (courtesy of Associate Professor Dr. Adibah Abdul Majid).

\subsection{Bacterial Strain and Growth Conditions}

E. faecalis ATCC 29212 was used in this study. The bacteria was grown on brain heart infusion (BHI) agar (Oxoid, UK) and passaged weekly. Cultures on BHI agar or in BHI broth (Becton Dickinson, USA) were incubated for $24 \mathrm{~h}$ at $37{ }^{\circ} \mathrm{C}$ in the presence of $5 \% \mathrm{CO}_{2}$ with $95 \%$ relative humidity (Shel Lab).

\subsection{Broth Microdilution Assays}

A range of two-fold dilutions of ginger oil in dimethyl sulfoxide (DMSO) (Acros Organics) and O. stamineus extract in purified water were prepared in sterile 96-well plates and inoculated with a standardized suspension of bacteria and incubated for $24 \mathrm{~h}$. There were eight concentrations of ginger oil $(5,2.5,1.25,0.63,0.31,0.16,0.08$ and $0.04 \mathrm{mg} / \mathrm{mL})$ and $O$. stamineus extract $(100,50,25,12.5,6.25,3.125,1.56$ and $0.78 \mathrm{mg} / \mathrm{mL})$ used in the viability assays described below, using broth microdilution technique.

The positive controls that were used to compare with the tested herbs were dilution series of amoxicillin or ampicillin (Sigma, USA), and $2.5 \%$ sodium hypochlorite $(\mathrm{NaClO})$. Amoxicillin or ampicillin was used because they are common antibiotics clinically used for patients with any periodontal, endodontic or perio-endo infections and $\mathrm{NaClO}$ is a common irrigant solution used in clinics to clean the root canal system due to its antibacterial properties.

After $24 \mathrm{~h}$ of exposure to studied herbs, the optical density (OD) of the growth turbidity was measured with a plate reader at $590 \mathrm{~nm}$ wavelength (Varioskan ${ }^{\circledR}$ Flash Microplate reader, Thermo Scientific, USA). The minimum concentration of the tested herbs that inhibits the growth of the E. faecalis after $24 \mathrm{~h}$ of incubation was recorded as the MIC. The growth inhibition of E. faecalis grown in suspension mode by the tested herbs was expressed as the ratio relative to positive control, $\mathrm{NaClO}$.

\subsection{Anti-Adhesion Assay and Biofilm Disruption Test}

For the anti-adhesion assay, both E. faecalis cultures $\left(1 \times 10^{5} \mathrm{CFU} / \mathrm{mL}\right)$ and the studied herbs were co-incubated into sterile 96-well plates in the anti-adhesion test for 6 and $24 \mathrm{~h}$ as described previously. In biofilm disruption test, E. faecalis biofilm was pre-grown in 96-well plates for $48 \mathrm{~h}$. The prepared herbs were added to the preformed biofilm and further incubated for $24 \mathrm{~h}$. Untreated E. faecalis acted as the negative control, while ampicillin $(5 \mathrm{mg} / \mathrm{mL})$ and $2.5 \% \mathrm{NaClO}$-treated biofilm acted as the positive controls for both tests. The biofilm formation in both tests was quantified using crystal violet staining. The absorbance of growth turbidity was measured with a plate reader at $590 \mathrm{~nm}$ wavelength.

\subsection{Quantification of Biofilm by Crystal Violet Staining}

Biofilm formation by E. faecalis was quantified according to Yamada et al. (2005) with modifications. The media containing unattached cells was gently pipetted out. Two hundred microliters of $0.1 \%$ crystal violet solution (Sigma, USA) was added and incubated for $15 \mathrm{~min}$ at room temperature. The crystal violet solutions 
were gently pipetted out and the wells were washed three times with purified water. Two hundred microliters of $80 \%$ ethanol $/ 20 \%$ acetone was later added. The solution was incubated for $10 \mathrm{~min}$ at room temperature. One-hundred microliters of the ethanol/acetone solution was transferred from each well to the new 96-well plates. The absorbance was measured with a plate reader at $590 \mathrm{~nm}$.

\subsection{Scanning Electron Microscopy (SEM)}

Ginger oil, $O$. stamineus extract, ampicillin and $\mathrm{NaClO}$ were added into bacteria culture and dispensed into 24-well plates where cut glass slides were placed. After incubation for $48 \mathrm{~h}$, glass slides bearing the attached $E$. faecalis cells were taken out and fixed with $2 \%$ glutaraldehyde using vapour fixation technique for $24 \mathrm{~h}$ at room temperature. After the fixation, the cells were rinsed several times with $0.1 \mathrm{M}$ phosphate buffered saline $(\mathrm{pH} 7)$ for a minimum of $10 \mathrm{~min}$. The cells were then dehydrated through a series of ethanol rinses $(50 \%, 70 \%, 90 \%$ and $100 \%$ ) for $10 \mathrm{~min}$ each. Finally, the cells were treated with hexamethyldisilazane for $10 \mathrm{~min}$, followed by air drying. The glass slides were attached to aluminium mounting stubs and sputter coated with gold. The morphology of the attached bacteria and control was examined and viewed under field emission scanning electron microscope (FESEM) (Zeiss Supra 55VP) using various magnifications.

\subsection{Statistical Analysis}

IBM-SPSS version 22 was used for the statistical analyses. The mean and the standard deviation of the absorbance readings were obtained, and independent-sample T-test was carried out to compare the mean values between the studied herbs and the controls. The level of significance was set at $p<0.05$.

\section{Results}

\subsection{MICs of The Tested Herbs, and Inhibition of E. faecalis Growth}

The MICs of ginger oil and O. stamineus extract against E. faecalis were 0.31 and $25 \mathrm{mg} / \mathrm{mL}$, respectively. The inhibition of E. faecalis grown in suspension mode by ginger oil was directly concentration-dependent, with $0.313 \mathrm{mg} / \mathrm{mL}$ of ginger oil showed significantly greater inhibition compared to $\mathrm{NaClO}$ (Figure 1a). In general, $O$. stamineus extract showed greater inhibition for all the tested concentrations, compared to $\mathrm{NaClO}$, although none of the tested concentrations exhibited significant growth inhibition compared to by $\mathrm{NaClO}$ (Figure 1b).

(a)

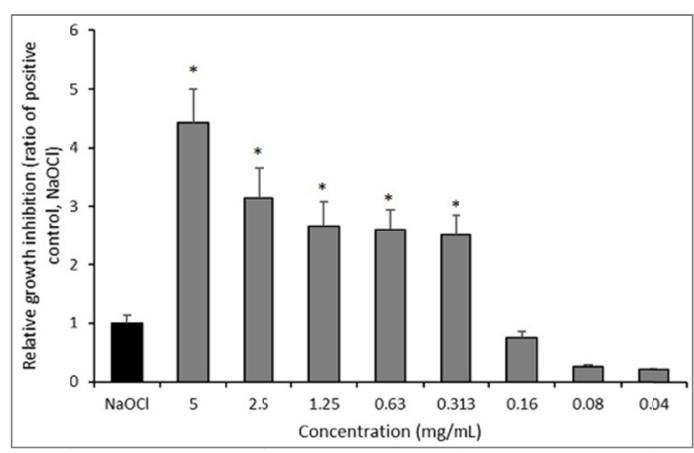

(b)

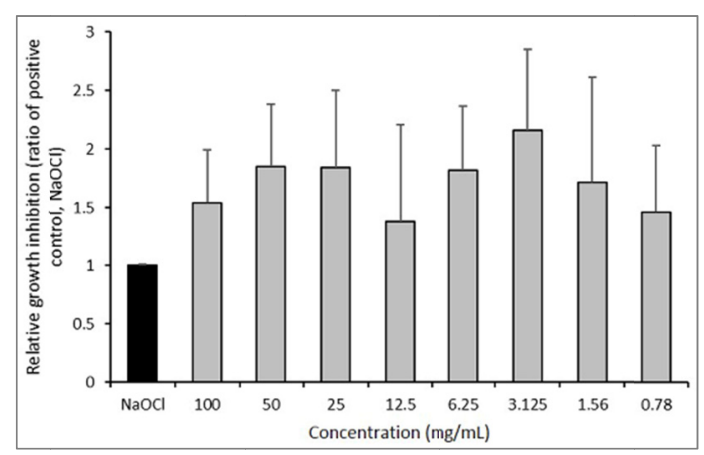

Figure 1. Growth inhibition of E. faecalis grown in suspension mode, following 24 h exposure with ginger oil (a) and $O$. stamineus extract (b)

Note. The growth inhibition for all the tested concentration was expressed as relative to inhibition by the positive control, 2.5\% NaClO. Error bars represent the mean $\pm \mathrm{SD}$ of two independent experiments performed in triplicates. * Significant differences $(p<0.05)$ between the ginger oil with $2.5 \% \mathrm{NaClO}$.

\subsection{Anti-Adhesion and Biofilm Disruption Activities}

Against $E$. faecalis, ginger oil exhibited inverse concentration-dependent anti-adhesion activity for both 6 and 24 $\mathrm{h}$ of exposure time (Figure 2a). Significant anti-adhesion activity was observed at lower ginger oil concentrations (0.04-0.08 $\mathrm{mg} / \mathrm{mL})$ compared to treatment with $\mathrm{NaClO}$. Comparatively, longer exposure time (24 h) showed greater anti-adhesion activity for almost all the tested ginger oil concentrations. For $O$. stamineus extract (Figure 2b), a $6 \mathrm{~h}$ exposure produced inverse concentration-dependent anti-adhesion activity for concentrations $0.78-12.5$ $\mathrm{mg} / \mathrm{mL}$. Conversely, the higher concentrations $(25-100 \mathrm{mg} / \mathrm{mL})$ showed a direct concentration-dependent 
anti-adhesion activity on E. faecalis. Similar to ginger oil, the $24 \mathrm{~h}$ exposure resulted in inverse-concentration dependent anti-adhesion activity against $E$. faecalis for all $O$. stamineus extract concentrations.

For biofilm disruption activities, ginger oil showed inverse concentration-dependent effects (Figure 2c), similar to its post- $6 \mathrm{~h}$ exposure anti-adhesion activity. $O$. stamineus extract showed inverse concentration-dependent activity at concentrations $0.78-6.25 \mathrm{mg} / \mathrm{mL}$, before the biofilm disruption activity increases at concentrations $12.5-50 \mathrm{mg} / \mathrm{mL}$ (Figure $2 \mathrm{~d}$ ).

(a)

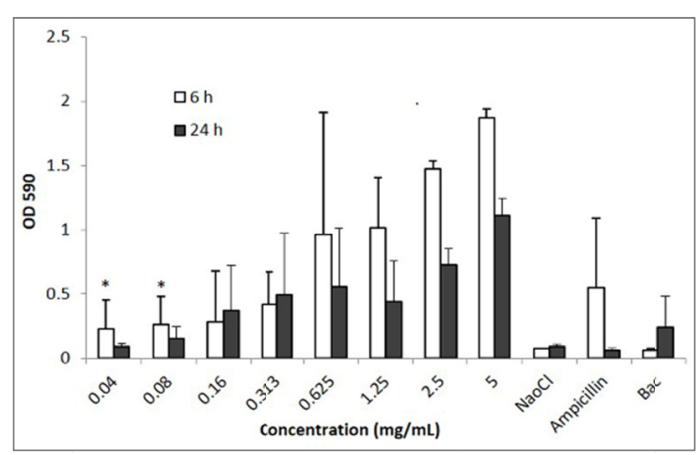

(c)

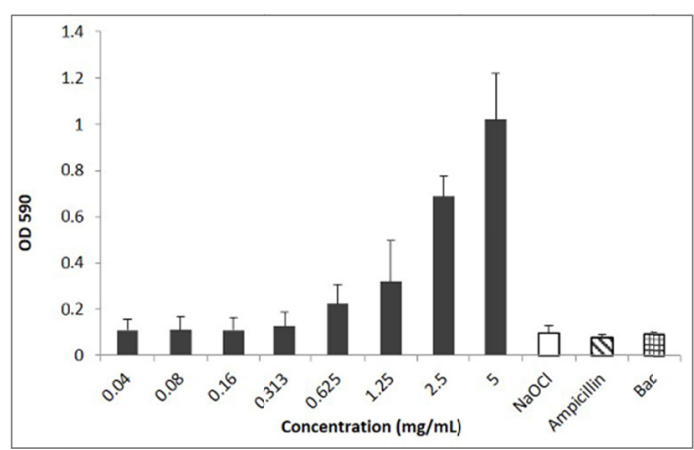

(b)

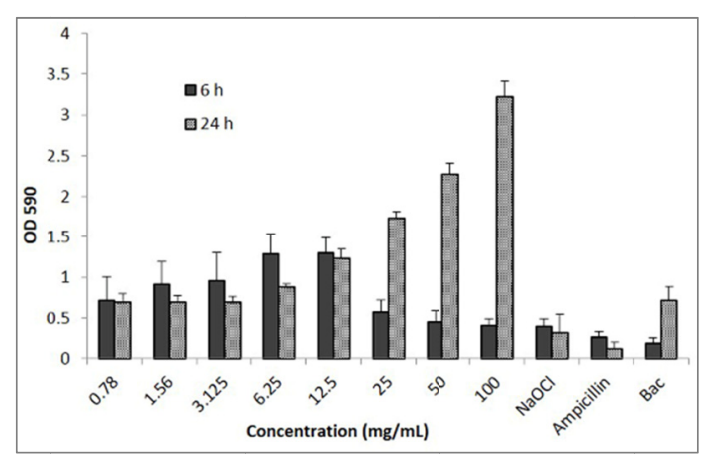

(d)

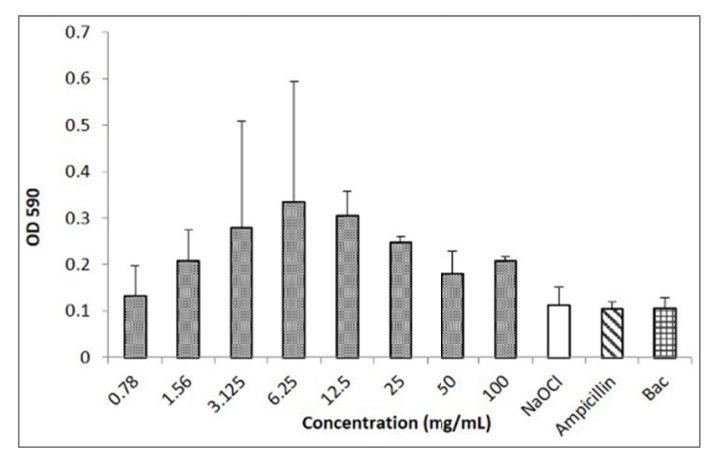

Figure 2. The anti-adhesion and biofilm disruption activities of ginger oil and $O$. stamineus extract on E. faecalis.

For anti-adhesion, biofilm formation was quantified following $6 \mathrm{~h}$ and $24 \mathrm{~h}$ exposure [(a) ginger oil, (b) $O$. stamineus]. For biofilm disruption activity, the remaining pre-formed biofilm following $24 \mathrm{~h}$ of exposure [(c) ginger oil, (d) O. stamineus] was quantified

Note. The concentrations the positive controls, $\mathrm{NaClO}$ and ampicillin, were $2.5 \%$ and $2.5 \mathrm{mg} / \mathrm{mL}$, respectively. Bac: untreated E. faecalis, as the negative control. Error bars represent the mean $\pm \mathrm{SD}$ of two independent experiments performed in triplicates. * Significant differences $(p<0.05)$ between the ginger oil with $\mathrm{NaClO}$. 


\subsection{SEM Analyses}

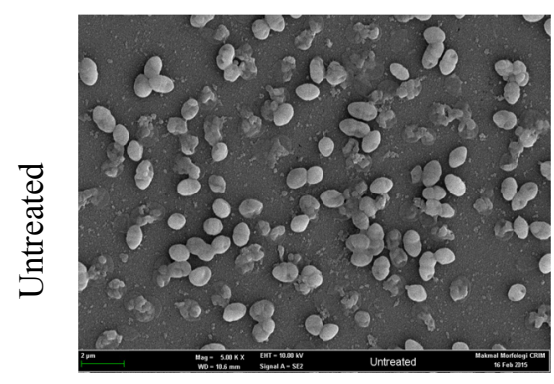

a

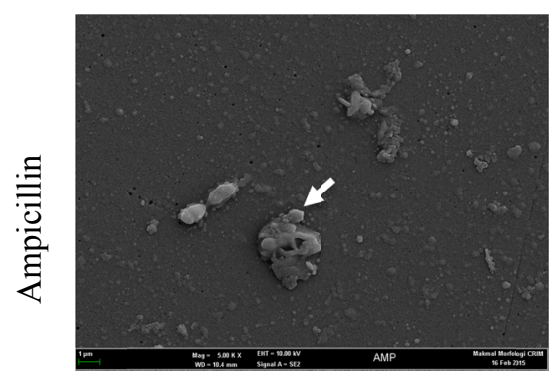

$\mathrm{c}$

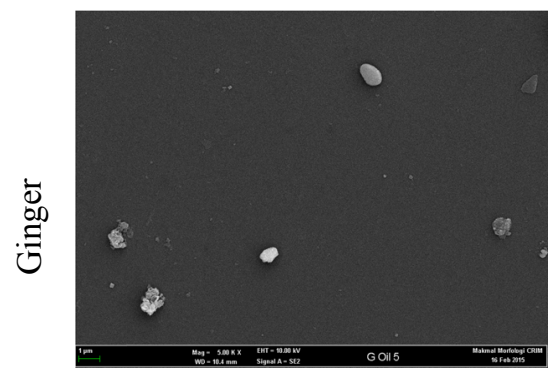

f

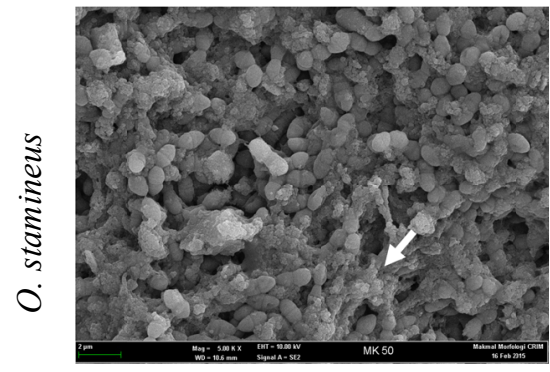

i

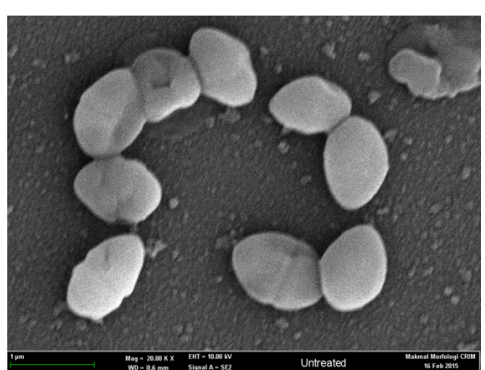

b

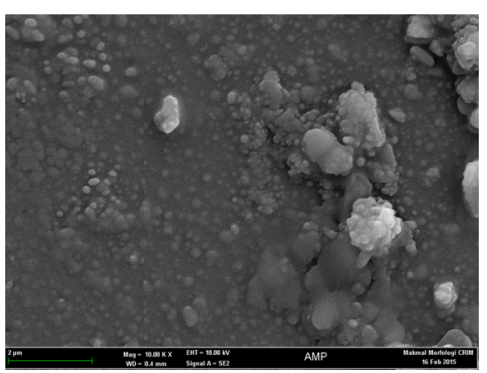

d

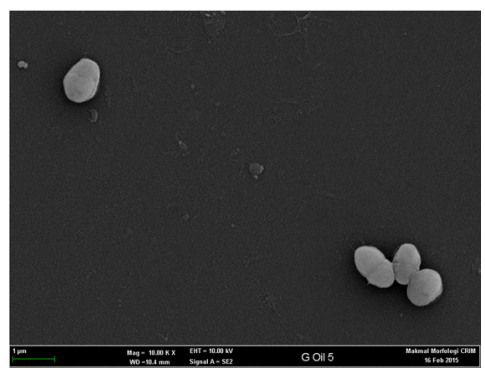

g

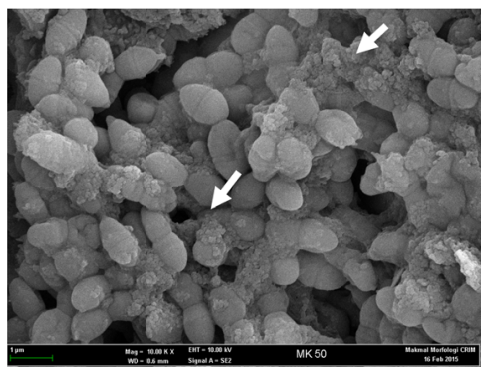

$\mathrm{j}$

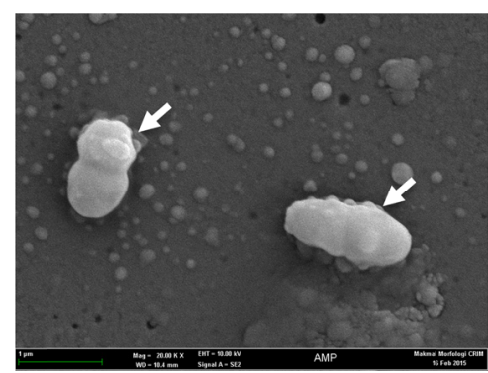

$\mathrm{e}$

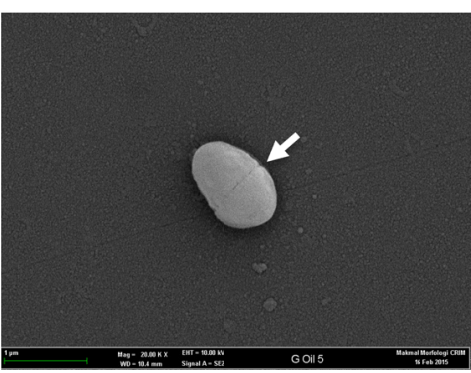

$\mathrm{h}$

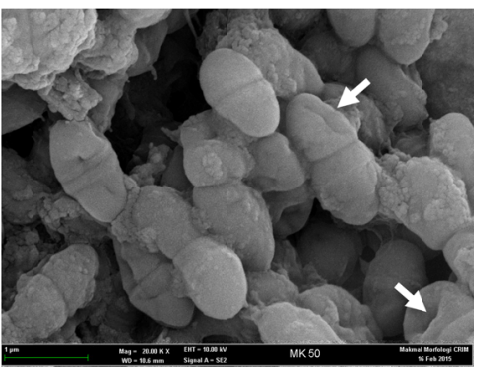

$\mathrm{k}$

Figure 3. SEM images of the treated E. faecalis compared to untreated bacteria and ampicillin

Note. Figure a, c, f, i at 5,000× magnification; Figure b, d, g, j at 10,000× magnification; Figure e, h, k at $20,000 \times$ magnification. The tested concentrations of ginger oil and $O$. stamineus were $5 \mathrm{mg} / \mathrm{mL}$ and $50 \mathrm{mg} / \mathrm{mL}$, respectively. The ampicillin concentration used was $2.5 \mathrm{mg} / \mathrm{mL}$.

Figure 3a shows attached bacterial cells of the untreated E. faecalis where at Figure 3b, the morphology of untreated bacterial cells was seen as ovoid-shaped, with smooth, regular cell surface. There is visibly less $E$. faecalis cell attachment in samples treated with ampicillin (Figures 3c and 3d) compared to untreated sample (Figures $3 \mathrm{a}$ and $3 \mathrm{~b}$ ). The cell surface of ampicillin-treated E. faecalis is irregular and the shape is elongated with nodular projections (Figure 3e, arrows). Visually, there were less attached cells in ginger oil treated samples (Figures $3 \mathrm{f}$ and $3 \mathrm{~g}$ ) compare to untreated samples (Figures 3a and 3b). Irregular E. faecalis cell surface was 
observed in the ginger oil-treated sample (Figure 3h, arrow). Contrastingly, numerous cells attachment was observed in $O$. stamineus-treated E. faecalis, apparently surrounded by particles (white arrowheads) which may have originated from $O$. stamineus extract (Figures $3 \mathrm{i}$ and $3 \mathrm{j}$ ). On higher magnification, the cell surfaces of $E$. faecalis showed irregular, pitted appearance (Figure 3k, arrow).

\section{Discussion}

E. faecalis are non-spore forming, fermentative, gram-positive organism (Suchitra \& Kundabala, 2006). They are usually associated with endodontics infection and implicated more commonly in persistent and secondary infections (Sedgley et al., 2005; Johnson et al., 2006). The persistent infection is caused by microorganisms that can resist intracanal antimicrobial procedures and can survive under extreme conditions (Narayanan \& Vaishnavi, 2010). The entry of $E$. faecalis into the root canal usually occurs during endodontic treatment, between appointments or even after root canal treatment (Stuart et al., 2006). E. faecalis possesses virulence factors such as lytic enzymes, cytolysin, aggregation substance, and lipoteichoic acid (Stuart et al., 2006). E. faecalis is able to form biofilm within the infected root canal system, which renders the bacteria resistant to phagocytosis, antibodies, and antimicrobials (Stuart et al., 2006; Liu 2010). The standard intracanal medicaments used in root canal treatment include calcium hydroxide and disinfectant such as sodium hypochlorite. However, E. faecalis biofilm has been reported to resist these common intracanal medicaments (Stuart et al., 2006; Liu, 2010; Sathorn et al., 2007; Haapasalo \& Shen, 2012), thus contributing to the failure of root canal treatment and persistent root canal infection. The current irrigant solution, sodium hypochlorite used in cleaning the root canal system is toxic to the surrounding soft tissue (Borzini et al., 2016). Thus, there is a need to find safer, gentler irrigant. E. faecalis has been reported to be resistant towards intracanal medicament such as calcium hydroxide when the $\mathrm{pH}$ is not maintained at a therapeutic level. This survival capacity of E. faecalis is facilitated by a functioning proton pump with the capacity to acidify the cytoplasm whenever the $\mathrm{pH}$ is high (Evans et al., 2002). Apart from that, starved E. faecalis were able to form a biofilm that was more resistant to $5.25 \%$ sodium hypochlorite than those in stationary and exponential phase (Liu, 2010).

Recently, plant materials have been studied widely as medicinal alternatives due to their natural origin, easy availability, efficacy, safety and reportedly lack of microbial resistance (Kamboj, 2000; Rahman et al., 2010). Ginger has been reported to exhibit antibacterial (M. N. J. Gulve \& N. D. G. Gulve, 2010; Mohamed et al., 2016), antioxidant (Bellik, 2014), antibiofilm (Kim et al., 2013), anti-gastrointestinal cancer (Prasad \& Tyagi, 2015) and antifungal properties (Ficker et al., 2003; Atai et al., 2009). As for O. stamineus, studies have reported on the antioxidant, anti-inflammatory (Akowuah et al., 2004; Yam et al., 2008), antifungal (Hossain et al., 2006) and antibacterial properties of this plant (Ho et al., 2010).

The examination of the growth inhibition effect of the studied herbs against E. faecalis was carried out using broth microdilution tests. The present study showed that both ginger oil and $O$. stamineus extract exhibited growth inhibition activity towards E. faecalis grown as a suspension culture. Comparatively, ginger oil showed a greater inhibitory effect to $O$. stamineus extract. This may be contributed by the herb preparations; ginger was used as essential oil, while $O$. stamineus was prepared by reconstituting the powdered plant with water, thus it can be regarded as a crude preparation of the herb. In the form of essential oil, the antibacterial components of ginger, namely gingerols and shogaol (Park, Bae, \& Lee, 2008; Wang et al., 2010) may be in higher concentrations, thus showing good growth inhibition activity. The O. stamineus water extract may have lower concentrations of its antibacterial component, rosmarinic acid, which is the primary polyphenol in O. stamineus leaf (Akuwoah et al., 2004).

In most oral diseases involving microorganisms, the initiation of a disease requires the pathogens to adhere to the tooth supporting structure or tooth surface ( $\mathrm{Li}$ et al., 2004). Substances that possess bacterial anti-adhesion activity hold a particular advantage in preventing the adhesion of bacteria to a surface, which is the required initial step for a pathogen to establish infection. In this study, both ginger oil and O. stamineus extract showed inverse dose-dependent anti-adhesion activity following both exposure time lengths of $6 \mathrm{~h}$ and $24 \mathrm{~h}$. Significant anti-adhesion activity relative to ampicillin was observed only at the two lowest ginger oil concentrations. At higher concentrations, more abundant E. faecalis adherence was observed for both herbs. It is suggested that there may be unknown compounds in ginger oil and $O$. stamineus extract when at higher concentrations, are able to promote $E$. faecalis adhesion. For $O$. stamineus it has no anti-adhesion activity following $6 \mathrm{~h}$ exposure. At 24 $\mathrm{h}$, both studied herbs generally showed lower anti-adhesion activity as the adhered cell layer may have got thicker. No significant biofilm disruption activity was observed for both studied herbs compared to positive control. This may simply because the preformed E. faecalis biofilm may have matured, where a high amount of extracellular polymeric matrix that encased the $E$. faecalis cells protects the bacteria from external insults, such as antimicrobial substances (Rickard et al., 2003). E. faecalis in suspension mode do not possess this protective 
mechanism, which may suggest a greater antibacterial activity of the herbs towards this growth mode than in the biofilm mode.

Our findings suggest that ginger oil, in lower concentrations, has more potential to be developed into antibacterial agent against bacteria in suspension growth mode rather than. The $O$. stamineus extract used in this study was more in a crude form, which may explain its low antibacterial activity. Previous studies which reported the protective effects of $O$. stamineus employed methanolic (Chun-Hoong et al., 2010; Malahubban et al., 2013) and ethanolic extracts (Alshawsh et al., 2012; Mohamed et al., 2012).

The findings on the antibacterial activity of ginger oil in this study were in contrast with the study by M. N. J. Gulve and N. D. G. Gulve (2010) which showed ginger extract has strong anti-bacterial activity against $E$. faecalis in agar diffusion test. Our study reported that ginger oil has a significant antibacterial effect on $E$. faecalis in suspension culture but not in biofilm mode. This may be due to different growth inhibition assays were used, sample size difference and ginger oil concentration difference. Park et al. (2008) showed that ginger extract can inhibit the growth of oral bacteria in suspension mode, which have good agreement with our results. One of the active agents of ginger, [10]-gingerol has been reported to cause damage to the membrane of enterococcus cells (Nagoshi et al., 2006). This damage was similar to the SEM findings in this study, where changes such as pitted cell surface and disintegrated cells were seen on E. faecalis following exposure to the studied herbs. According to Lim et al. (2009), hydroethanolic ginger extract exhibits potent antibacterial activity against Gram-positive and Gram-negative bacteria. In the past, essential oils had been demonstrated to be as effective as antimicrobial agents to use in oral care (Tufekci et al., 2008). An important characteristic of essential oils and their components is their hydrophobicity, which enables them to partition into and disturb the lipid bilayer of the bacterial cell membrane, rendering them more permeable, leading to leakage of cell contents (Burt, 2004). According to Unlu et al. (2010), cells incubated in essential oil for $48 \mathrm{~h}$ showed obvious changes in their morphology and loss of adhesion, which was similar to our findings for $E$. faecalis treated with ginger.

\section{Conclusion}

Z. officinale and O. stamineus showed effective antibacterial effect towards E. faecalis, particularly in growth inhibition and anti-adhesion, but less effective in disrupting preformed biofilm. Comparatively, $Z$. officinale oil has more potential to be developed as antibacterial agent against $E$. faecalis in suspension culture compared to $O$. stamineus extract.

\section{Acknowledgements}

We thank Ms. Nurul Nuha Kamal Bahrain and Ms. Nur Amirah Azizan, Department of Clinical Oral Biology, Faculty of Dentistry, UKM for their assistance. This research was supported by Ministry of Agriculture and Agro-Based Industry, Malaysia, through NKEA Research Grant Scheme (NH0513DO19).

\section{References}

Akowuah, G. A., Zhari, N., Sadikun, A., \& Khamsah, S. M. (2004). Sinensetin, eupatorin, 3'-hydroxy 5, 6, 7, 4'-tetramethoxyflavone and rosmarinic acid contents and antioxidative effect of Orthosiphon stamineus from Malaysia. Food Chemistry, 87, 559-566. https://doi.org/10.1016/j.foodchem.2004.01.008

Alshawsh, M. A., Abdulla, M. A., Ismail, S., Amin, Z. A., Qader, S. W, Hadi, H. A., \& Harmal, N. S. (2012). Free radical scavenging, antimicrobial and immunomodulatory activities of Orthosiphon stamineus. Molecules, 8, 5385-95. https://doi.org/10.3390/molecules17055385

Atai, Z., Atapour, M., \& Mohseni, M. (2009). Inhibitory effect of ginger extract on Candida albicans. American Journal of Applied Science, 6, 1067-1069. https://doi.org/10.3844/ajassp.2009.1067.1069

Azizi, A., Aghayan, S., Zaker, S., Shakeri, M., Entezari, N., \& Lawaf, S. (2015). In vitro effect of Zingiber officinale extract on growth of Streptococcus mutans and Streptococcus sanguinis. International Journal of Dentistry, 2015, 489842. https://doi.org/10.1155/2015/489842

Bellik, Y. (2014). Total antioxidant activity and antimicrobial potency of the essential oil and oleoresin of Zingiber officinale Roscoe. Asian Pacific Journal of Tropical Disease, 4(1), 40-44. https://doi.org/10.1016/ S2222-1808(14)60311-X

Borzini, L., Condò, R., De Dominicis, P., Casaglia, A., \& Cerroni, L. (2016). Root canal irrigation: Chemical agents and plant extracts against Enterococcus faecalis. The Open Dentistry Journal, 10, 692-703. https://doi.org/10.2174/1874210601610010692 
Burt, S. (2004). Essential oils: Their antibacterial properties and potential applications in foods-A review. International Journal of Food Microbiology, 94, 223-253. https://doi.org/10.1016/j.ijfoodmicro.2004. 03.022

Chun-Hoong, H., Ismail N., Shaida-Fariza, S., \& Ahmad, R. (2010). In vitro antibacterial and antioxidant activities of Orthosiphon stamineus Benth. extracts against food-borne bacteria. Food Chemistry, 122, 1168-1172. https://doi.org/10.1016/j.foodchem.2010.03.110

Evans, M., Davies, J. K., Sundqvist, G., \& Figdor, D. (2002). Mechanisms involved in the resistance of Enterococcus faecalis to calcium hydroxide. International Endodontic Journal, 35, 221-228. https://doi.org/ 10.1046/j.1365-2591.2002.00504.x

Ficker, C., Smith, M. L., \& Akpagana, K., (2003). Bioassay-guided isolation and identification of antifungal compound from ginger. International Journal of Phytotherapy Research, 17, 897-903. https://doi.org/ $10.1002 /$ ptr. 1335

Ghasemzadeh, A., Jaafar, H. Z. E., \& Rahmat, A. (2015). Optimization protocol for the extraction of 6-gingerol and 6-shogaol from Zingiber officinale var. rubrum Theilade and improving antioxidant and anticancer activity using response surface methodology. BMC Complementary and Alternative Medicine, 15, 258. https://doi.org/10.1186/s12906-015-0718-0

Gulve, M. N. J., \& Gulve, N. D. G. (2010). Comparison of antimicrobial efficacy of ginger extract and 2\% sodium hypochlorite against Enterococcus faecalis using agar diffusion method. The Journal of the Indian Dental Association, 4, 347-349.

Haapasalo, M., \& Shen, Y. (2010). Current therapeutic options for endodontic biofilms. Endodontic Topics, 22, 79-98. https://doi.org/10.1111/j.1601-1546.2012.00281.x

Hossain, M. A., Zhahri, I., Atiqur, R., \& Sun, C. K. (2008). Chemical composition and anti-fungal properties of the essential oil and crude extraction O. stamineus Benth. Industrial Crops and Products, 27, 328-334. https://doi.org/10.1016/j.indcrop.2007.11.008

Johnson, E. M., Flannagan, S. E., \& Sedgley, C. M. (2006). Coaggregation interactions between oral and endodontic Enterococcus faecalis and bacterial species isolated from persistent apical periodontitis. Journal of Endodontic, 32, 946-950. https://doi.org/10.1016/j.joen.2006.03.023

Kamboj, V. P. (2000). Herbal medicine. Current Science, 78, 35-51.

Karuppiah, P., \& Rajaram, S. (2012). Antibacterial effect of Allium sativum cloves and Zingiber officinale rhizomes against multiple-drug resistant clinical pathogens. Asian Pacific Journal of Tropical Biomedicine, 2, 597-601. https://doi.org/10.1016/S2221-1691(12)60104-X

Kassebaum, N. J., Smith, A. G. C., Bernabé, E., Fleming, T. D., Reynolds, A. E., Vos, T., ... Collaborators, G. O. H. (2017). Global, regional, and national prevalence, incidence, and disability-adjusted life years for oral conditions for 195 countries, 1990-2015: A systematic analysis for the global burden of diseases, injuries, and risk factors. Journal of Dental Research, 96(4), 380-387. https://doi.org/10.1177/0022034517693566

Kim, H. S., \& Park, H. D. (2013). Ginger extract inhibits biofilm formation by Pseudomonas aeruginosa PA14. PLoS ONE, 8(9), e76106. https://doi.org/10.1371/journal.pone.0076106

Kim, J. S, Lee, S. I., Park, H. W., Yang, J. H., Shin, T. Y., Kim Y.-C., ... Kim, D. K. (2008). Cytotoxic components from the dried rhizomes of Zingiber officinale Roscoe. Archives of Pharmacal Research, 31, 415-418. https://doi.org/10.1007/s12272-001-1172-y

Lete, I., \& Allué, J. (2016). The effectiveness of ginger in the prevention of nausea and vomiting during pregnancy and chemotherapy. Integrative Medicine Insights, 11, 11-17. https://doi.org/10.4137/IMI.S36273

Li, J., Helmerhorst, E. J., Leone, C. W., Troxler, R. F., Yaskell, T., Haffajee, A. D., ... Oppenheim, F. G. (2004). Identification of early microbial colonizers in human dental biofilm. Journal of Applied Microbiology, 97, 1311-1318. https://doi.org/10.1111/j.1365-2672.2004.02420.x

Lim, Z., Cheng, J. L., Lim, T. W., Teo, E. G., Wong, J., George, S., \& Kishen, A. (2009). Light activated disinfection: An alternative endodontic disinfection strategy. Australian Dental Journal, 54, $108-114$. https://doi.org/10.1111/j.1834-7819.2009.01102.x

Liu, H. (2010). Biofilm formation capability of Enterococcus faecalis cells in starvation phase and its susceptibility to sodium hypochlorite. Journal of Endodontic, 36, 630-635 https://doi.org/10.1111/ j.1834-7819.2009.01102.x 
Malahubban, M., Alimon, A. R., Sazili, A. Q., Fakurazi, S., \& Zakry, F. A. (2013). Phytochemical analysis of Andrographis paniculata and Orthosiphon stamineus leaf extracts for their antibacterial and antioxidant potential. Tropical Biomedicine, 30, 467-80.

Mohamed, E. A. H., Siddiqui, M. J. A., Ang, L. F., Sadikun, A., Chan, S. H., Tan, S. C., ... Yam, M. F. (2012). Potent $\alpha$-glucosidase and $\alpha$-amylase inhibitory activities of standardized $50 \%$ ethanolic extracts and sinensetin from Orthosiphon stamineus Benth as anti-diabetic mechanism. BMC Complementary and Alternative Medicine, 12, 176. https://doi.org/10.1186/1472-6882-12-176

Mohamed, H. G., Gaafar, A. M., \& Soliman, A. S. (2016). Antimicrobial activities of essential oil of eight plant species from different families against some pathogenic microorganisms. Research Journal of Microbiology, 11, 28-34. https://doi.org/10.3923/jm.2016.28.34

Mohammed, A. M. A., Salmah, I., Zahra, A. A., Suhailah, W. Q., Hamid, A. H., \& Nabil, S. H. (2012). Free radical scavenging antimicrobial and immunomodulatory activities of Orthosiphon stamineus of Orthosiphon stamineus Benth. Molecules, 17, 5385-5395. https://doi.org/10.3390/molecules17055385

Nagoshi, C., Shiota, S., Kuroda, T., Hatano, T., Yoshida, T., Kariyama, R., \& Tsuchiya, T. (2006). Synergistic effect of [10]-gingerol and aminoglycosides against vancomycin-resistant enterococci (VRE). Biological \& Pharmaceutical Bulletin, 29, 443-447. https://doi.org/10.1248/bpb.29.443

Narayanan, L. L., \& Vaishnavi, C. (2010). Endodontic microbiology. Journal of Conservative Dentistry, 13, 233-239. https://doi.org/10.4103/0972-0707.73386

Olah, N. K., Radu, L., Mogos, C., Hanganu, D., \& Gocan, S. (2003). Phytochemical and pharmacological studies on Orthosiphon stamineus Benth. (Lamiaceae) hydroalcoholic extracts. Journal of Pharmaceutical and Biomedical Analysis, 33, 17-123. https://doi.org/10.1016/S0731-7085(03)00227-9

Park, M., Bae, J., \& Lee, D. S. (2008). Antibacterial activity of (10)-gingerol and (12)-gingerol isolated from ginger rhizome against periodontal bacteria. Journal of Phytotherapy Research; 22, 1446-49. https://doi.org/10.1002/ptr.2473

Patel, R. V., Thaker, V. T., \& Patel, V. K. (2011). Antimicrobial activity of ginger and honey on isolates of extracted carious teeth during orthodontic treatment. Asian Pacific Journal of Tropical Biomedicine, 1(Suppl. 1), S58-S61. https://doi.org/10.1016/S2221-1691(11)60124-X

Perry, L. M., (1980). Medicinal plants of East and Southeast Asia: Attributed properties and uses. Massachusetts Institute of Technology Press, Cambridge, Mass, USA.

Rahman, M. S. A., Thangaraj, S., Salique, S. M., Khan, K. F., \& Natheer, S. E. (2010). Antimicrobial and biochemical analysis of some spices extract against food spoilage pathogens. International Journal of Food Safety, 12, 71-75.

Rickard, A. H., Gilbert, P., High, N. J., Kolenbrander, P. E., \& Handley, P. S. (2003). Bacterial coaggregation: An integral process in the development of multi-species biofilms. Trends in Microbiology, 11, 94-100. https://dx.doi.org/10.1016/S0966-842X(02)00034-3

Sasidharan, I., \& Menon, A. M. (2010). Comparative chemical composition and antimicrobial activity fresh and dry ginger oils (Zingiber officinale Roscoe). International Journal of Current Pharmaceutical Research, 2, 40-43.

Sathorn, C., Parashos, P., \& Messer, H. (2007). Antibacterial efficacy of calcium hydroxide intracanal dressing: A systematic review and meta-analysis. International Endodontic Journal, 40, 2-10. https://doi.org/10.1111/ j.1365-2591.2006.01197.x

Sebiomo, A., Awofodu, A. D., Awosanya, A. O., Awotona, F. E., \& Ajayi, A. J. (2011). Comparative studies of antibacterial effect of some antibiotics and ginger (Zingiber officinale) on two pathogenic bacteria. Journal of Microbiology and Antimicrobials, 3, 18-22.

Sedgley, C. M., Molander, A., \& Flannagan, S. E. (2005). Virulence, phenotype and genotype characteristics of endodontic Enterococcus spp. Oral Microbiology Immunology, 20, 10-19. https://doi.org/10.1111/j.1399302X.2004.00180.X

Shim, S., Kim, S., Choi, D. S., Kwon, Y. B., \& Kwon, J. (2011). Anti-inflammatory effects of [6]-shogaol: Potential roles of HDAC inhibition and HSP70 induction. Food Chemistry Toxicology, 49, 2734-2740. https://doi.org/10.1016/j.fct.2011.08.012 
Stuart, C. H., Schwartz, S. A., Beeson, T. J., \& Owatz, C. B. (2006). Enterococcus faecalis: Its role in root canal treatment, failure and current concepts in retreatment. Journal of Endodontics, 32, 93-98. https://doi.org/ 10.1016/j.joen.2005.10.049

Suchitra, U., \& Kundabala, M. (2006). Enterococcus faecalis: An endodontic pathogen. Endodontology, 18, 11-13.

Takahashi, M., Inouye, S., \& Abe, S. (2011). Anti-Candida and radical scavenging activities of essential oils and oleoresins of Zingiber officinale Roscoe and essential oils of other plants belonging to the family Zingiberaceae. Drug Discoveries Therapeutics, 5, 238-245. https://doi.org/10.5582/ddt.2011.v5.5.238

Tezuka, Y., Stampoulis, P., Banskota, A. H., Awale, S., Tran, K. Q., Saiki, I., \& Kadota, S. (2000). Constituents of the Vietnamese medicinal plant Orthosiphon stamineus. Chemical and Pharmaceutical Bulletin, 48, 1711-1719.

Tufekci, E., Casagrande, Z. A., Lindauer, S. J., Fowler, C. E., \& Williams, K. T. (2008). Effectiveness of an essential oil mouth rinse in improving oral health in orthodontic patients. The Angle Orthodontist, 78, 294-298. https://doi.org/10.2319/040607-174.1

Unlu, M., Ergene, E., Unlu, G. V., Zeytinoglu, H. S., \& Vural, N. (2010). Composition, antimicrobial activity and in vitro cytotoxicity of essential oil from Cinnamomum zeylanicum Blume (Lauraceae). Food Chemical Toxicology, 48, 3274-3280. https://doi.org/10.1016/j.fct.2010.09.001

Wang, H. M., Chen, C. Y., Chen, H. A., Huang, W. C., Lin, W. R., Chen, T. C., .. Chen, Y. H. (2010). Zingiber officinale (ginger) compounds have tetracycline-resistance modifying effects against clinical extensively drug-resistant Acinetobacter baumannii. Phytotherapy Research, 24, 1825-30. https://doi.org/10.1002/ ptr.3201

Yam, M. F., Ang, L. F., Basir, R., Salman, I. M., Ameer, O. Z., \& Asmawi, M. Z. (2009b). Evaluation of the anti-pyretic potential of Orthosiphon stamineus Benth standardized extract. Inflammopharmacology, 17, 50-54. https://doi.org/10.1007/s10787-008-8038-3

Yam, M. F., Ang, L. F., Salman, I. M., Ameer, O. Z., Lim, V., Ong, L. M., .. Basir, R. (2009a). Orthosiphon stamineus leaf extract protects against ethanol-induced gastropathy in rats. Journal of Medicinal Food, 12, 1089-1097. https://doi.org/10.1089/ jmf.2008.0005

Yam, M. F., Asmawi, M. Z., \& Basir, R. (2008). An investigation of the anti-inflammatory and analgesic effects of Orthosiphon stamineus leaf extract. Journal of Medicinal Food, 11, 362-368. https://oi.org/10.1089/ jmf.2006.065

Yam, M. F., Basir, R., Asmawi, M. Z., \& Ismail Z. (2007). Antioxidant and hepatoprotective effects of Orthosiphon stamineus Benth. standardized extract. American Journal of Chinese Medicine, 35, 115-126. https://doi.org/10.1142/S0192415X07004679

Yamada, M., Ikegami, A., \& Kuramitsu, H. K. (2005). Synergistic biofilm formation by Treponema denticola and Porphyromonas gingivalis. Federation of European Microbiological Societies Microbiology Letters, 250, 271-277. https://doi.org/10.1016/j.femsle.2005.07.019

\section{Copyrights}

Copyright for this article is retained by the author(s), with first publication rights granted to the journal.

This is an open-access article distributed under the terms and conditions of the Creative Commons Attribution license (http://creativecommons.org/licenses/by/4.0/). 